\title{
ACQUISITION CENTRALITY, LOCUS OF CONTROL AND THE INFLUENCE OF RELIGION IN EVERYDAY LIFE: THE CASE OF URBAN CONSUMER CLASS OF BANGLADESH
}

\author{
MUHAMMAD REHAN MASOOM \\ School of Business \& Economics, United International University, Bangladesh \\ PhD Researcher, Bangladesh University of Professionals, Bangladesh
}

() 2020 Muhammad Rehan Masoom

This is an open access article distributed under the Creative Commons Attribution-NonCommercial-NoDerivs license (http://creativecommons.org/licenses/by-nc-nd/3.0/)

DOI: $10.1515 /$ eras-2020-0006

\begin{abstract}
The present study addresses the consequences of materialistic value-orientation (i.e. Acquisition Centrality) on the effect of the sense of control on religious experiences of the urban consumer class of Bangladesh. The central thesis is that economic transformation may contribute to the materialistic value-orientation and exert a control on the social experience; nonetheless, it would not exert any effect between the relationship of the Locus of Control and the role of religion. To test the thesis, the research investigates; given the economic growth begets acquisition centrality on a larger scale and these values, in return, often form the new purpose of social lives and emerge as a potential social force of modernity. Can religion as a century-old social institution continue to have strong-hold on the definition of social reality? To answer the question, this Cross-sectional research administered a survey of 1246 respondents from ten randomly selected distinct areas of Dhaka city and analyzed the data within a structural equation modeling (SEM) framework. The findings suggest that the people with high (External) sense of control are more likely to be influenced by their religious experiences and the people with low (Internal) sense of control have high Acquisition Centrality; Acquisition Centrality strengthened the influence of External Locus of Control on the influence of religion.
\end{abstract}

\section{Keywords}

Acquisition Centrality, Religiosity, Locus of Control, Dhaka, Urban Dwellers, Structural Equation Modeling (SEM)

\section{Introduction}

Material belongings have social significance since they serve beyond their instrumental usage in regular lives and add symbolic value to the Social Identity and Selfexpression (Burroughs, Drews, \& Hallman, 1991). Hence, possession can itself become the 'goal of life' to ensure the significance of social existence in the society, and 'Acquisition Centrality' as an element of the cultural system tends to form. 'Acquisition Centrality' is commonly defined as "a way of thinking that gives too much importance to material possessions rather than to spiritual or intellectual things" (Merriam-Webster Dictionary). This indicates "possessions assume a central place in a person's life and are believed to provide the greatest sources of satisfaction and dissatisfaction" (Belk, 1984, 291). It reflects "the importance a person places on possessions and their acquisition as a necessary or desirable form of conduct to reach desired end states, including happiness" (Fournier \& Richins, 1991). While acquisition of materials act "as essential means for discovering and furthering personal values and goals of life," it can also be used as a tool to "generate the envy and admiration of 
others or to achieve status" (Csikszentmihalyi \& Rochberg-Halton, 1978, 8). It is found that establishing Social Identity and Self-expression based on the acquisition of materials make people feel susceptible to external factors such as social approval or public acknowledgment (Kashdan \& Breen, 2007). Eventually people are inclined to sense that outcomes of any event or activities are outside of their control.

An individual's sense of control or in Rotter's (1954) framework, the 'Locus of Control' (LOC) can be internal or external. Locus of control can be defined as "a generalized expectancy for internal as opposed to external control of reinforcements" (Lefcourt, 1966, 27). People who count their success as a simple outcome of their hard work and assume they have the firm grip on their lives have an internal locus of control. In contrast, people who attribute their achievement, accomplishment or incompetence and failure to the outside forces have an external locus of control. Another way to say, external locus of control is the degree to which people consider their life-events are controlled by the external forces such as fate, the family head, the people around or the divinity. Religion is an external force that influences individual's social and personal life. Recently, Mirowsky and Ross (2006), while outlining the social forces of psychological distresses, define sense of control as "a learned, generalized expectation that outcomes are contingent on one's own choices and actions" (Mirowsky \& Ross, 2006). A recent debate revolves around the role of religion to the sense of personal control with the notion that religion as an external force influences individual's social and personal life (Ellison, Schieman, \& Bradshaw, 2012). Not to mention, it has been a longstanding theme in Social sciences, findings its root in Durkheim's theory of Anomie and Max Weber's concept of rationalization.

Religion is defined as "any cognition, affect, or behavior that arises from an awareness of, or perceived interaction with, supernatural entities that are presumed to play an important role in human affairs" (McCullough \& Willoughby, 2009, 71). Though it seems similar, nonetheless there are two distinct dimensions within the construct of religion - Religiosity and Spirituality (Hill \& Pargament, 2003). While spirituality indicates the inward and personal aspect of religion, the religiosity is being conceptualized as the outward, manifested and institutional aspect of it. Hence, spirituality is more of a psychological notion, and religiosity is the sociological term "to refer to the numerous aspects of religious activity, dedication, and belief in religious doctrine" (Zafar, 2011, 105). It indicates "the degree to which beliefs in specific religious values and ideal are held and practiced by an individual" (Delener, 1990, 27). Perhaps Charles Glock's five-dimensional scheme of religiosity is the best known and widely used empirical tool to address religiosity. He indicates that the beliefs, the experience of religious emotions, the specific religious practices, knowledge about the basic tenets of faith as well as religious scriptures, and interpersonal relationship are the five essential dimensions of religiousness (Glock, 1962). It has been found that certain aspects of religious involvement may limit the feelings of control, while other facets of religious engagement may strengthen a sense of control (Ellision \& Burdette, 2011). Arguably, religion as a social institution has become less effective with the development of consumer society (Gauthier, 2009). In the consumer society, the commodities and consumption transform the values, needs and even the behavior of the individual in such a way that people begin to recognize themselves in the acquisition of their commodities (Marcuse, [1964] 2014). In Herbert Marcuse's term, "the very mechanism which ties an individual to his society has changed, and social control is anchored in the new needs which it has produced" (Marcuse, [1964] 2014, 9). Not surprising, the fundamental notion of sociological analysis of consumption and consumerism has its origin in Marxian Framework in general and Marx's theory of commodity, in particular. 
Notable Scholar Erich Fromm (1955) once wrote, "Modern man, if he dared to be articulate about his concept of heaven, would describe a vision which would look like the biggest department store in the world, showing new things and gadgets, and himself having plenty of money with which to buy them" (Fromm, 1955, 135). The pursuance of acquisition as an aim in life preoccupies people in incessant upward social similitude with a strenuous feeling of never possessing enough and trying hard to gain more to meet the culturally defined standards. Since social life is shaped by the complex interplay of normative values originated in the culture of society, decoding the interplay between or among the dominant social values reveals the very nature of the social existence itself. Assuming that materialistic values are a complex social phenomenon, premises, such as the degree of religiosity and the low sense of control over the social experience may have been affected by it. A materialist judge acquisition of properties as the centrality of his or her existence, similarly, an individual who exhibits low in the sense of control enlist outside factors such as luck or fate on their social experiences. In addition, unlike external structural constraints, the internal compulsions such as a low sense of control are endogenous due to the experiences of social hurdles and often emerge as a source of negativity for individuals in their own right (Strickland \& Shaffer, 1971). Hence, the question is, if the people are being exposed to materialistic values, will that produce any effect on the relationship between religiosity and the sense of control.

The relationship between religiosity and the sense of control is yet to be conclusive, and research suggests that religion can impede as well as expedite the development of the sense of control. Traditionally, religion is believed to be hampering the personal sense of control primarily because religious dogmas and absolutistic world-views discourage sense of confidence in one's capabilities, and encourages attributing outcome of any events related to external entities such as God or Satan (Ellis, 1983). Second, believe in afterlife deemphasize earthly accomplishments such as economic gain, career success or high social status that may otherwise have contributed to high sense of control (Stark \& Brainbridge, 1996). Sometimes, involvement in particular religious communities may posit strong expectation to follow a lifestyle that the follower may feel inadequate to pursue and begin to feel low sense of control (Pargament, 2002). Finally, the idea of 'sinfulness' may lead to interpret any problem of life as divine punishment and feel lower level of mastery over own living (Musick, 2000).

Recently, an alternate result has also been found to be true where religious persons have shown high sense of control. First, Religion, as an influential philosophical orientation, affects the perception of the world and makes the suffering reasonable and helps a person to see the assertive aspects that have come from stressful circumstances and renders a way to make more benign re-attributions (Pargament, 1997). This "collaborative control" where the individuals with the partnership of God deal the problems, makes them feel that their ability to adapt to reality and take constructive action is being magnified (Krauss, Hamzah \& Idris, 2012). Second, religiosity acts as an agent to shape the events of lives when things appear to be out of control (Fiori, Brown, Cortina \& Antonucci, 2006). Finally, those who are religious and have a firm belief in the afterlife are found to have more sense of control than the rest (Ellison \& Burdette, 2011). It may primarily be because, since they believe the divine is assisting them in steering their personal hurdles, hence it is not pertinent to be in control of the personal matters in fuller extent. The recent researches mostly treated Acquisition Centrality as a manifested component of materialism, as an independent variable with the notion that materialism induces detrimental effects on a person's subjective evaluation of his or her state of affairs (Hudders \& Pandelaere, 2012). Previous literature affirms the growing materialism in a developing economy like Bangladesh and its adverse effects on the factors of social lives like religion (Masoom \& Sarker, 2017). The other-oriented personality or the persons characterized by an external locus of control are more likely to possess high 
materialism primarily due to the resentfulness of others (Hunt, Kernan, Chatterjee \& Florsheim, 1990). Though it has been found that materialism is negatively associated with subjective well-being, and in some way, it is a source of stress that has detrimental effects on the sense of control (Kózka \& Przybyła-Basista, 2016), nonetheless, it is yet to be conclusive. Because a person who exhibits high materialistic value-orientation is supposed to attribute proficiency as an internal factor of self rather than depending on the context. Hence, an alternative finding remains a logical possibility as well.

\section{Research Context and Hypothesis}

Given the economic growth begets acquisition centrality on a larger scale and these values, in return, often form the new purpose of social lives and become a potential social force of modernity, can religion as a century-old social institution continue to have stronghold on the definition of social reality? And, can the self-belief on the control of social experience that people have, have the capacity to minimize its effects due to their materialistic values? It is hypothesized that the transitional economy drives to form materialistic valueorientation, and people intend to expect more from themselves. Religion, on the other hand, leads to spiritual satisfaction and internal locus of control, devoid the feeling of depression to others rather than on their own. People of Bangladesh, especially the middle class living in Dhaka city, have one foot embedded in the past and hold their religious beliefs rather firmly, conversely many of their social activities have embraced the contemporary customs that confer consumerism. In addition, due to some socio-economic and political hindrances, the control of externality may remain a potent factor for decision making. It is relatively unknown, if acquisition centrality begins to form, does it reduce the effect of religiosity on control of externality? If it is found to be true, then a general conclusion may be drawn, that more people give value to buying new things, more will form the internal locus of control and become less religious. In this line of thought, the following hypotheses are formed:

H1. If people have an external locus of control, then they will have a high Acquisition centrality.

H2. If people have an external locus of control, then they will have a high influence of religion.

H3. If people develop Acquisition centrality, then they will have a low influence of religion.

H4. Acquisition centrality reduces the effect of religion on the sense of control.

\section{Method}

\section{Research Design}

This quantitative venture is a causal research that intends to unveil the relationship among Acquisition Centrality, Locus of Control and Religious Influence based on primary data gathered by structured questionnaire through a survey on 1246 respondents. Precisely, Locus of Control is treated as an exogenous variable in every case whereas religious influence is considered as an endogenous variable. Acquisition Centrality treaded as endogenous variable for Locus of control, exogenous variable for religious influence and compound variable in the structured equation. The research will seek to explain the subject matter being researched to answer why the situation is as such and would try to ensure empirical association between the variables and nonspuriousness. To address the dynamic interplay among these social phenomena, the survey instrument is formulated and the key constructs, such as Acquisition Centrality and Religious influence are analyzed in the existing literature. The internal consistency, dimensionality, composite reliability and discriminant validity of the 
underlying construct will be made before testing the proposed hypotheses, such as whether the 'Acquisition Centrality' plays any meditating role between the relationship of locus of control and the influence of religion. A confirmatory factor analysis (CFA) is used to assess the items of the questionnaire, and within a structural equation modeling (SEM) framework the hypotheses are tested.

\section{Sample Design}

Given that the research is causal in nature, it requires at least some sort of randomization where the population can be attributed as finite number and sample can be attributed as unbiased predictors to meet the requirement of linear regression. Due to the absence of sample-frame, the construction of sample designs and estimators are considered superpopulation model (Isaki \& Fuller, 1982). There are fifty sub-offices for the postal service in Dhaka city, and ten are randomly selected from them. From the selected zones, the shopping malls are outlined and randomly selected to enlist the respondents since they adequately represent as the materialistic and form acquisition centrality. To formulate the superpopulation, the surveyors count the number of people visiting the malls at least for three consecutive days on three distinct times of the day to make a rough estimation. If the number of population is being estimated, each kth shoppers will be counted as the respondents. Since the study will administer a survey with at least 1000 respondents from ten different zones of Dhaka city, therefore at least 100 respondents are considered from the shopping malls of each postal zone. Hence, the value of $\mathrm{k}$ can be determined by the total number of shoppers of a particular shopping mall divided by 100. It is estimated that the Greater Dhaka has a population of at least 18 million as of 2016, and with 95 percent Confidence Level with a 5 percent Confidence Interval, 384 respondents would be sample size. Since hypotheses will be tested in SEM and constructs are going to be validated by confirmatory factor analysis, hence a larger sample size is considered instead of considering the adequate size.

\section{Instruments \& Procedure}

Methodologically speaking, measuring the normative values of the common people is a complex issue and basic prerequisite for the successful investigation of religiosity requires identifying the distinct aspects of measurement tool. A 25 items structured questionnaire is designed to elicit the response from the target population with the view that a mall-intercept method of data collection is applied and the less the number of items will engage the shoppers, reduce the time of collecting data from a large sample and eliminate the nonresponse error. Marsha Richins and Scott Dawson (1992) most successfully measured the degree of 'Materialistic Value-orientation' with an 18 items scale (Richins \& Dawson, 1992). The current study selected 7 items that are part of 'Acquisition Centrality' subscale, primarily because it is the strongest constructs of the scale and found to be the most reliable. Julian Rotter (1966) is the pioneer to formulate a scale to measure the locus of control of people (Rotter, 1966) and this 13 items scale is the most widely used one to measure the internal versus external locus of control. Sethi and Martin Seligman's (1993) 'Religiousness Scale' is the most comprehensive tool to investigate the level of religiosity of people with different faith. The study considered 5 items to measure the influence of religion in everyday life. Selected 12 items of the two constructs, acquisition centrality and religious influence are evaluated by 7-point Likert format starting from 'Strongly Agree' to 'Strongly Disagree.' A confirmatory factor analysis (CFA) is used to assess the validity and reliability of 12 selected items for the constructs of acquisition centrality and religious influence. The Internal-External Locus of Control Scale by Rotter (1966) is a limited item forced-choice test that includes "correct-incorrect" answer pairs, and we need to estimate the degree by of LOC as proposed. 
Hence, despite being ambiguous at times, we cannot, due to its nature, estimate the statistical validity of the scale. However, the worldwide acceptance of the scale makes it less susceptible to validate empirically in different context. Hence, the research proceeds without validating the construct. Within a structural equation modeling (SEM) framework, Acquisition Centrality and Religious Influence are the latent factors, whereas Locus of control is equated as an observed variable. From the modification indices, we allowed only two pairs of errorterms to covary to improve model fit indices.

\section{Results}

\section{Respondents}

All participants $(\mathrm{n}=1246)$ in the survey are Bangladeshi by birth and aged between 18 and 82 with an average of $25.76( \pm 8.144)$ (some of the respondents, about 5.1 percent, did not mention their age). Majority of the respondents, about 82.7 percent belongs to the $18-29$ age group. Of the respondents 787 (63.2\%) were male, and 459 (36.8\%) were female. According to religious faith, about 92.5 percent were Muslims, 5.5 percent were following Sanata Dharma (Hinduism), and about 2 percent were Christians. Please consider table 1 for detail.

\section{Table 1. Demographic profile of the respondents}

\begin{tabular}{|l|l|r|r|r|}
\hline Factor & \multicolumn{1}{|c|}{ Category } & Frequency & \multicolumn{1}{c|}{ Percent } & \multicolumn{1}{c|}{ Valid Percent } \\
\hline \multirow{5}{*}{ Age-group } & $18-29$ & 978 & 78.5 & 82.7 \\
\cline { 2 - 5 } & $30-39$ & 116 & 9.3 & 9.8 \\
\cline { 2 - 5 } & $40-49$ & 53 & 4.3 & 4.5 \\
\cline { 2 - 5 } & $50-59$ & 25 & 2.0 & 2.1 \\
\cline { 2 - 5 } & Above 60 & 11 & .9 & .9 \\
\cline { 2 - 5 } & Total & $\mathbf{1 1 8 3}$ & $\mathbf{9 4 . 9}$ & $\mathbf{1 0 0 . 0}$ \\
\hline \multirow{5}{*}{ Gender } & Male & 787 & 63.2 & 63.2 \\
\cline { 2 - 5 } & Female & 459 & 36.8 & 36.8 \\
\cline { 2 - 5 } & Total & $\mathbf{1 2 4 6}$ & $\mathbf{1 0 0 . 0}$ & $\mathbf{1 0 0 . 0}$ \\
\hline \multirow{5}{*}{ Religion } & Islam & 1152 & 92.5 & 92.5 \\
\cline { 2 - 5 } & Hinduism & 69 & 5.5 & 5.5 \\
\cline { 2 - 5 } & Christianity & 25 & 2.0 & 2.0 \\
\cline { 2 - 5 } & Total & $\mathbf{1 2 4 6}$ & $\mathbf{1 0 0 . 0}$ & $\mathbf{1 0 0 . 0}$ \\
\hline
\end{tabular}

\section{Validity and Reliability of Acquisition Centrality and Religious Influence}

All seven items to measure Acquisition Centrality are found valid (p.<0.001); five items strongly $(\beta>0.5)$ contributing to measure the latent construct, and two items seem (Q7 \& Q8) weak $(0.35<\beta<0.5)$. The value of Cronbach's Alpha (0.789) and Composite Reliability $(0.787)$ are acceptable $(\alpha>0.7)$, however Average Variable Extracted (0.358) fail to reach the acceptability (AVE>0.5). Similarly, all five items to measure Religious Influence in everyday life are found valid $(\mathrm{p} .<0.001)$ and items strongly $(\beta>0.5)$ contributing to measure the latent construct. The value of Cronbach's Alpha (.788) and Composite Reliability (0.771) are acceptable $(\alpha>0.7)$, however Average Variable Extracted $(0.406)$ fail to reach the acceptability (AVE>0.5). Nonetheless, despite AVE is less than 0.5, we can proceed with the analysis (though with caution) since composite reliability is higher than 0.6 , and as Claes Fornell and David Larcker (1981) indicates that the convergent validity of the construct can be considered as adequate (Fornell \& Larcker, 1981). Please consider table 2. 
Table 2. Standardized Regression Weights, Cronbach's Alpha, Average Variable Extracted and Composite Reliability of the Factors and Items

\begin{tabular}{|c|c|c|c|c|c|}
\hline \multirow{3}{*}{$\begin{array}{l}\text { Item } \\
\text { Code }\end{array}$} & Factors and Items & $\begin{array}{l}\text { Acquisition } \\
\text { Centrality }\end{array}$ & $\begin{array}{l}\text { Religious } \\
\text { Influence }\end{array}$ & S.E. & $t^{*}$ \\
\hline & & & & & \\
\hline & Acquisition Centrality & & & & \\
\hline Q1 & $\begin{array}{l}\text { I'd be happier if I could afford to buy } \\
\text { more things. }\end{array}$ & 0.748 & & 0.05 & 23.076 \\
\hline Q2 & I like a lot of luxury in my life. & 0.71 & & 0.05 & 22.014 \\
\hline Q3 & $\begin{array}{l}\text { Buying things give me a lot of } \\
\text { pleasure. }\end{array}$ & 0.679 & & 0.05 & 21.199 \\
\hline Q4 & $\begin{array}{l}\text { It sometimes bothers me quite a bit } \\
\text { that I can't afford to buy all the things I } \\
\text { like. }\end{array}$ & 0.615 & & 0.05 & 19.371 \\
\hline Q5 & $\begin{array}{l}\text { My life would be better if I owned } \\
\text { certain things I don't have. }\end{array}$ & 0.548 & & 0.05 & 17.338 \\
\hline Q6 & $\begin{array}{l}\text { I like to own things that impress } \\
\text { people. }\end{array}$ & 0.399 & & 0.05 & 12.657 \\
\hline \multirow[t]{2}{*}{ Q7 } & $\begin{array}{l}\text { Some of the most important } \\
\text { achievements in life include acquiring } \\
\text { material possessions. }\end{array}$ & 0.379 & & 0.05 & 12.024 \\
\hline & Religious Influence & & & & \\
\hline Q17 & $\begin{array}{l}\text { My religion influences what social } \\
\text { activities I undertake }\end{array}$ & & 0.634 & 0.04 & 19.076 \\
\hline Q16 & $\begin{array}{l}\text { My religion influences whom I } \\
\text { associate with }\end{array}$ & & 0.566 & 0.05 & 20.331 \\
\hline Q15 & $\begin{array}{l}\text { My religion influences what I eat and } \\
\text { drink }\end{array}$ & & 0.716 & 0.07 & 17.611 \\
\hline Q14 & My religion influences what I wear & & 0.719 & 0.07 & 17.632 \\
\hline \multirow[t]{4}{*}{ Q12 } & $\begin{array}{l}\text { My religion influences the important } \\
\text { decisions of my life }\end{array}$ & & 0.526 & 0.05 & 14.496 \\
\hline & Cronbach's alpha & .789 & .788 & & \\
\hline & Ave & 0.358 & 0.406 & & \\
\hline & Composite reliability & 0.787 & 0.771 & & \\
\hline
\end{tabular}

*All values are significant (p.<0.001)

\section{Model Fit Indices}

The Rotter internal-external locus of control scale (1966) is used to measure the individual differences in a generalized expectancy or belief to the extent of external control. Since Julian Rotter devised the scale in such a way that the Locus of control of any individual is manifested through the score calculated as per direction, hence it is treated as the observed variable rather than latent construct. Acquisition Centrality and Religious Influence are the latent factors in the model constructed with measurable items that are validated. The fit indices of the proposed Structured Equation Model indicate that we can conclude based on the covariance and correlation values estimated. The value of chi-square $\left(\chi^{2}=249.821 ; \mathrm{df}=61\right.$; $\mathrm{n}=1246 ; \mathrm{p}<0.001)$ indicates slighter difference between the expected and observed covariance matrices, nonetheless since the test result may include the possibility of accepting an inappropriate model due to sample size, other fit measures need to be taken into consideration 
(Gatignon, 2010). The Minimum discrepancy-degrees of freedom ratio (CMIN/DF=4.095), Comparative-fit index ( $\mathrm{CFI}=0.954)$, Goodness-of-fit-index $(\mathrm{GFI}=0.968)$, Adjusted goodness of fit index (AGFI=0.952), Root mean square error of approximation (RMSEA=0.05, PCLOSE=0.501), and Standardized Root Mean Square Residual (SRMR=0.0424) values confer the level of validity of the modified model. In General, any value above 0.9 of CFI, GFI, and AGFI is considered as acceptable model-fit (Schreiber, Stage, King, Nora, \& Barlow, 2006).

Table 3. The goodness of fit indices for the Model

\begin{tabular}{|l|c|}
\hline Model Fit Index & Survey Model \\
\hline Minimum discrepancy/ degrees of freedom (CMIN/DF) & 4.095 \\
\hline Comparative-fit index (CFI) & 0.954 \\
\hline Goodness-of-fit-index (GFI) & 0.968 \\
\hline Adjusted goodness of fit index (AGFI) & 0.952 \\
\hline $\begin{array}{l}\text { Root mean square error of approximation (RMSE) } \\
\text { [pclose=0.501] }\end{array}$ & 0.05 \\
\hline Standardized Root Mean Square Residual (SRMR) & 0.0424 \\
\hline
\end{tabular}

Notes - The model fit indices of the survey model estimated after drawing the covariances between the errorterms (2) in accordance with the proposed modification indices.

\section{Hypotheses}

Based on the test and re-test in the Structured Equation Modeling, it is found that if people's sense of control increase, Acquisition centrality increases (H1 rejected). Conversely, if people's sense of control decreases, it will increase the influence of religion on everyday life ( $\mathrm{H} 2$ accepted). Acquisition centrality and the influence of religion on everyday life are positively related (H3 rejected). Introducing Acquisition centrality as a compound variable in the equation to measure the mediation effect, it is found that the strength of the relationship between the variables increased. This implies that, if a religious person develops acquisition centrality, his or her generalized expectancy or belief to the extent of external control becomes greater (H4 rejected). The strength of the relationship between Locus of control and Acquisition centrality remains more or less stable before and after introducing the compound variable $\left(\chi 2=-0.165\right.$, p. $<0.001 \& \chi^{2}=-0.164$, p. $\left.<0.001\right)$ and the strength of relationship between Acquisition centrality and religious influences $(\chi 2=-0.095, \mathrm{p} .<0.05)$ enhanced $(\chi 2=-$ 0.112 , p. $<0.05)$ after introducing the compound variable. Please consider table 4 and figure 1 for Hypotheses Test Result from Structured Equation Model and conclusion draw from the result. 
Table 4. Hypotheses Test Result (Structured Equation Model)

\begin{tabular}{|c|c|c|c|c|c|c|}
\hline Sr. & $\begin{array}{l}\text { Exogenous } \\
\text { Variable }\end{array}$ & $\begin{array}{l}\text { Endogenous } \\
\text { Variable }\end{array}$ & $\begin{array}{l}\text { Compound } \\
\text { Variable }\end{array}$ & Value & $\begin{array}{l}\text { Level of } \\
\text { Significance }\end{array}$ & Conclusions \\
\hline H1 & $\begin{array}{l}\text { Locus of } \\
\text { Control }\end{array}$ & $\begin{array}{l}\text { Acquisition } \\
\text { Centrality }\end{array}$ & None & -0.165 & 0.001 & $\begin{array}{l}\text { Internal Loc leads } \\
\text { Acquisition } \\
\text { Centrality }\end{array}$ \\
\hline H2 & $\begin{array}{l}\text { Locus of } \\
\text { Control }\end{array}$ & $\begin{array}{l}\text { Religious } \\
\text { Influence }\end{array}$ & None & 0.086 & 0.05 & $\begin{array}{l}\text { External Loc leads } \\
\text { religious Influence }\end{array}$ \\
\hline $\mathbf{H 3}$ & $\begin{array}{l}\text { Acquisition } \\
\text { Centrality }\end{array}$ & $\begin{array}{l}\text { Religious } \\
\text { Influence }\end{array}$ & None & 0.095 & 0.05 & $\begin{array}{l}\text { Acquisition } \\
\text { Centrality leads } \\
\text { religious Influence }\end{array}$ \\
\hline H4 & $\begin{array}{l}\text { Locus of } \\
\text { Control }\end{array}$ & $\begin{array}{l}\text { Religious } \\
\text { Influence }\end{array}$ & $\begin{array}{l}\text { Acquisition } \\
\text { Centrality }\end{array}$ & 0.105 & 0.001 & $\begin{array}{l}\text { Acquisition } \\
\text { Centrality } \\
\text { strengthened the } \\
\text { influence of } \\
\text { External Loc on } \\
\text { religious Influence }\end{array}$ \\
\hline
\end{tabular}

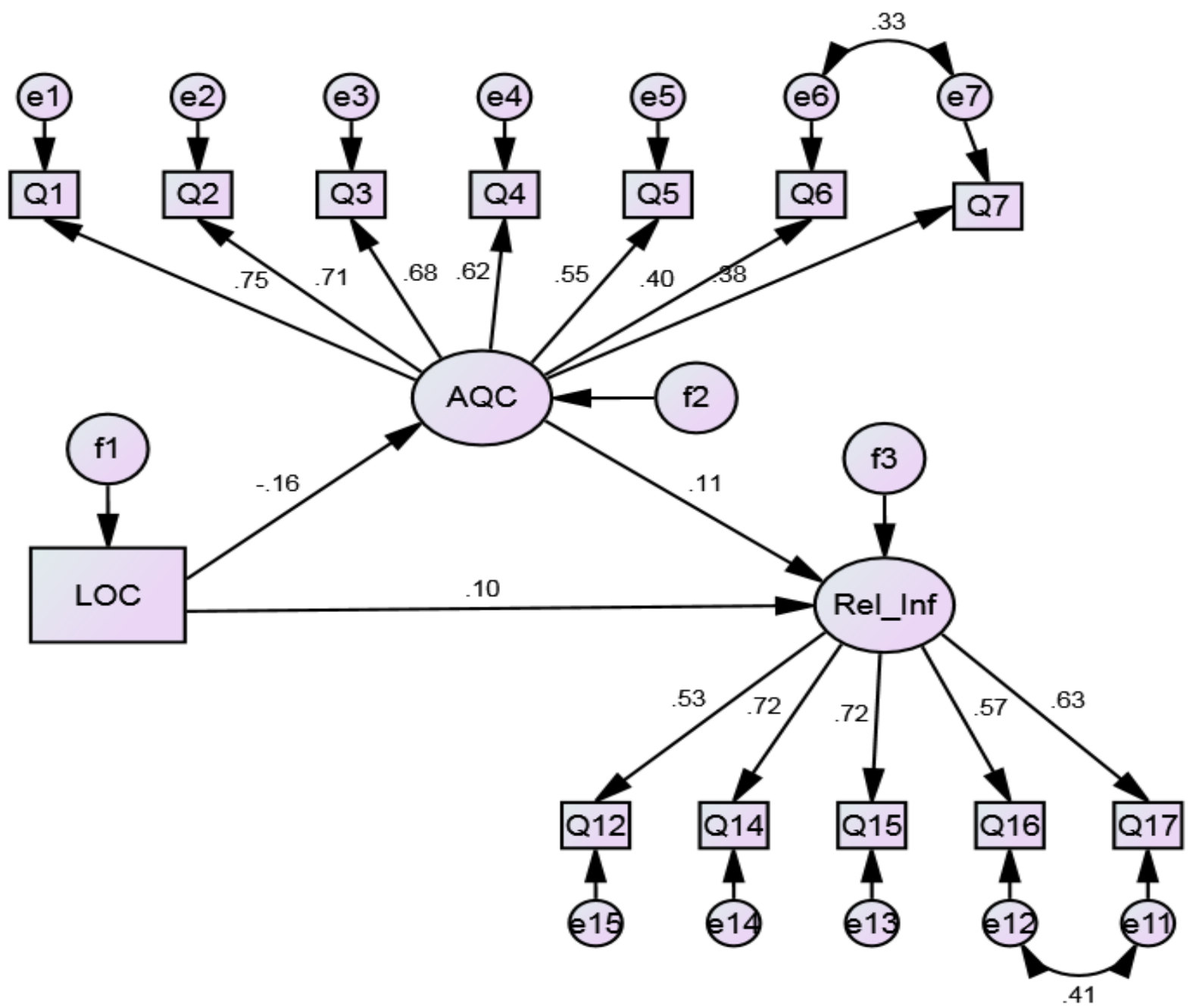

Figure 1. The effect of Acquisition centrality between LOC and the religious influence

Note. With 91 distinct sample moments and 30 distinct parameters, Chisquare $=249.821$, Degrees of freedom $=61$, Probability level $=.001$. 


\section{Discussions}

Once the classical sociologists such as Marx and Durkheim predicted that the grip of religion to control the social lives would be faded due to Modernization. Instead, the role of religion has not faded, rather transformed and the resurgence becomes a salient feature of it. Hence, it is a probable scenario that traditional institutions such as religion may persist despite the economic transformation, and modern materialistic values may emerge but not replace the existing ones (DiMaggio, 2009). Industrialization may not direct all the societies to the same trajectories primarily because cultural heritage also plays a pivotal role to shape the nature of social change. Max Weber (1904) argued that the formation of Social institutions including economy has often been tremendously influenced by traditional religious values. Hence, as Hamilton (1994) writes: "What we witness with the development of a global economy is not increasing uniformity, in the form of a universalization of Western culture, but rather the continuation of civilizational diversity through the active reinvention and reincorporation of non-Western civilizational patterns" (Hamilton \& Shin, 2015, 184). Hence, given the economic growth begets acquisition centrality on a larger scale and these values, in return, often form the new purpose of social lives and becomes a potential social force of modernity, can religion as century-old social institution continue to have strong-hold on the definition of social reality and the sense of control? Our thesis, at the onset was that economic transformation may contribute to the materialistic value-orientation and exert a control on the social experience; nonetheless, it wound not posit any effect between the relationship of the sense of control and the role of religion. Bangladesh, in general and Dhaka it particular is the ideal case to study, primarily because these urban dwellers have one foot embedded in the past and hold their religious beliefs rather strongly, conversely many of their social activities have embraced the contemporary customs that confer consumerism. In addition, due to some socio-economic and political hindrances, the control of external forces may remain a potent factor for decision making. The results of the research are somehow different and, on a few occasions, quite contrary. Nonetheless, we can provide an explanation of the findings.

Economic progression of Bangladesh (based on the World Bank's estimation in 2014, a lower-middle-income nation, with annual earnings of at least $\$ 1,046$ ) perceptibly echoes by the consumption habits of its people. People are spending much more than usual on their living and of devouring of pleasure. Conspicuous consumption is rampant, so does the expenses for basic amenities. Reports suggest that near about two million people of the country join up to the middle-class and affluent consumers every year (Munir, Muehlstein \& Nauhbar, 2015). This newly ascending middle class is not only very positive about the prospect of the economic state of the country and value international brands, but they also tend to step onto the 'digital bandwagon' (Masoom \& Sarker, 2017). For example, appealing fast-food chains like KFC, Pizza Huts, Takeout, Gloria Jean's Coffee, or Columbus Coffee Shop have an increasing number of outlets in metropolitan areas, and people are moving more towards eating out than eating at home. This is particularly true for the urban dwellers in Dhaka city. Therefore, it would not be exaggerating to state, the growing orientation of rising consumerism may incorporate 'Acquisition Centrality' as a socio-cultural value, where acquiring material belongings begin to function as the essential component for the search for 'Good Life' (Richins, 1994). However, this is merely one side of the picture.

Where the middle class is rising with its ever-increasing consumption habit, there are around 53 million people still living below the poverty line (The World Bank, 2016). Where thousands of students of English medium schools are learning western tradition and lifestyle, there are millions of students studying in thousands of Quami Madrasas across the country, getting substandard education (Ahmed, 2015). On one side, people love to show to which political parties they are affiliated with, conversely, millions of people gather to the non- 
political demonstration of Hefajat-e-Islam as well (Rahman \& Marjan, 2014). Further, the clash between two divisions of Tabligh Jamaat on the Airport Road in Dhaka on December 2018 confers the critical role of religious values in the social atmosphere. There is always a thin line kept between politics and religion, or between modern culture and traditional Bengali values, nonetheless, very often the actions undertaken by people intend to blur that fine line. Therefore, there is less room undoubting that 'religiosity' is one of the central traits of the cultural value system of this country, where almost all individuals indicate that religion is very important for their lives (Munir et al., 2015). However, due to its socio-economic diversity, it is no surprise that a broad range of perspectives emerged in the normative culture of this country. It is often said that "Bangladesh is a complex country, and freedom of religion or belief has manifold facets" (Bielefeldt, 2015).

The Gallup surveys indicate hundreds of nations having a per-capita GDP below $\$ 5,000$ are found to be the most religious countries as well (Crabtree, 2010), and people of Bangladesh are not far from this reality. It is found that regardless of age, nationality, gender or ethnicity, the majority of people that suffer poverty or deprivation feel that their lives are controlled by outside factors, hence confirming the 'External Locus of Control.' Presumably, an urging need to address the variables like 'pessimistic beliefs,' 'learned helplessness', 'social isolation' and 'external locus of control' has emerged as the central thesis in some ongoing research in Bangladesh (Masoom, 2017). Previous research suggests that people with a higher intrinsic religious stance, have a stronger belief in internal control of reinforcement; similarly, those who regard their religion as very personal and meaningful, are like to interpret their lifesituations as the reflection of their religious behavior and beliefs (Strickland \& Shaffer, 1971). Religiosity is often associated with an external locus of control (McCormick, Hoekman, \& Smith, 2000), and materialistic values reduce the degree of religiousness (Masoom \& Sarker, 2017). Hence, the question is, if the urban dwellers of Bangladesh are being exposed to materialistic values due to economic growth, will that bring any changes to the effect of religiosity on the sense of control.

Although it becomes predictable that materialistic value-orientation can be incorporated as a social phenomenon into the realm of sociological analysis, nonetheless very few studies focus on its relationship with the level of religiosity and low sense of control that materialists suffer due to the value-orientation as such. The available literature is not only inconclusive about the relationship between materialism and normative values but also less than adequate to interpret the nature of the emerged relationships in the psychosocial context (Burroughs \& Rindfleisch, 2002). Where the mastery of fate has a strong connotation on the degree of religiousness, nonetheless, studying the role of materialistic value-orientation in general and acquisition centrality in particular on the normative landscape of society has been virtually ignored. While most studies uncover a negative association among the materialistic values and religiosity, these findings are yet to be empirically conclusive across countries, indicating the socio-cultural context need to be addressed (Baker, Moschis, Ong, \& Pattanapanyasat, 2013). Hence, focusing on moderating and mediating variables in the domain of normative components is supposed to be significant. The result of the current study can be explained in this line of thought. Precisely, the urban consumer class allows their faith to control their social activities, Social relations, their food habit, preferences of apparel and the decisions they make. These influences intensify if people are attributing their lives' events as dominated by external factors. However, the pursuance of acquisition as an aim in life makes the urban consumers attribute proficiency as an internal factor of self and become less concerned about the external forces. Acquisition Centrality as a new life philosophy does not negate the influence of locus of control on religion, rather it intensifies it. Though the findings are found to be significant, the strength of the relationships are rather weak, nonetheless the 
research has both ontological concerns as it describes a vivid picture of social reality and Epistemological outcome such as the tool to measure the variables of interest. Besides, it is basic research to advance fundamental knowledge about the social world and may not have an immediate use to resolve a pressing issue by addressing the questions that the practitioners want answers. Like the most basic research, the study would be the source of the methods, theories, and ideas to address the value-shift of contemporary Bangladesh. It not only answered of how to measure (a) Acquisition Centrality, (b) Religious Influence and (c) Locus of Control in Bangladesh context but also addressed about the relationships among these social phenomena.

\section{ACKNOWLEDGEMENT}

This research was funded by INSTITUTE OF ADVANCED RESEARCH (IAR), United International University, United City, Madani Avenue, Badda, Dhaka 1212, Bangladesh; grant number "IAR/01/19/BE/04".

\section{CONFLICTS OF INTEREST}

The author declares that he has no conflicts of interest, neither financial nor nonfinancial and neither professional nor personal, regarding this paper. The founding sponsor had no role in the design of the study; in the collection, analyses, or interpretation of data; in the writing of the manuscript, and in the decision to publish the results.

\section{REFERENCES}

Ahmed, M. (2015, May 24). 1.4 m students' study in 14,000 Qawmi madrasas. Prothom-Alo. Retrieved from http://en.prothom-alo.com/bangladesh/news/67081/14-lakh-students-study-in-14-000-Qawmi-madrasas

Baker, A. M., Moschis, G. P., Ong, F. S., \& Pattanapanyasat, R. (2013). Materialism and life satisfaction: The role of stress and religiosity. Journal of Consumer Affairs, 47(3), 548-563. Retrieved from https://onlinelibrary.wiley.com/doi/abs/10.1111/joca.12013

Bielefeldt, H. (2015). Preliminary findings of Country Visit to Bangladesh by Heiner Bielefeldt, Special Rapporteur on freedom of religion or belief. Retrieved April 1, 2017, from http://www.ohchr.org/EN/NewsEvents/Pages/DisplayNews.aspx?NewsID=16399

Burroughs, J. E., \& Rindfleisch, A. (2002). Materialism and Well-Being: A Conflicting Values Perspective. Journal of Consumer Research. https://doi.org/10.1086/344429

Crabtree, S. (2010). Religiosity Highest in World's Poorest Nations. Retrieved April 11, 2017, from http://www.gallup.com/poll/142727/religiosity-highest-world-poorest-nations.aspx

Delener, N. (1990). The effects of religious factors on perceived risk in durable goods purchase decisions. Journal of Consumer Marketing. https://doi.org/10.1108/EUM0000000002580

DiMaggio, P. (2009). Identities, Boundaries, and Social Ties. Contemporary Sociology: A Journal of Reviews. https://doi.org/10.1177/009430610703600311

Ellison, C. G., \& Burdette, A. M. (2011). Religion and the Sense of Control among U.S. Adults. Sociology of Religion, 73(1), 1-22. https://doi.org/10.1093/socrel/srr035

Ellison, Christopher G., Schieman, S., \& Bradshaw, M. (2012). The association between religiousness and psychological well-being among older adults: Is there an educational gradient? In Religion and Inequality in America: Research and Theory on Religion's Role in Stratification. https://doi.org/10.1017/CBO9781139226479.017

Fiori, K. L., Brown, E. E., Cortina, K. S., \& Antonucci, T. C. (2006). Locus of control as a mediator of the relationship between religiosity and life satisfaction: Age, race, and gender differences. Mental Health, Religion and Culture. https://doi.org/10.1080/13694670600615482

Fournier, S., \& Richins, M. L. (1991). Some Theoretical and Popular Notions Concering Materialsim. Journal of Social Behavior and Personality, 6(6), 403-414. https://doi.org/10.1017/CBO9781107415324.004

Fromm, E. (1955). The sane society. New York: Rinehart \& Company, Inc. Retrieved from https://www.worldcat.org/title/sane-society/oclc/255482

Gatignon, H. (2010). Statistical analysis of management data. Boston, MA: Kluwer Academic Publishers. 
https://doi.org/10.1007/978-1-4419-1270-1

Gauthier, F. (2009). Religion in Contemporary Consumer Societies. Revue Du Mauss Permanente, (September). Retrieved from http://www.journaldumauss.net/?Religion-in-Contemporary-Consumer

Hamilton, G. G., \& Shin, S. I. (2015). Demand-responsive industrialization in East Asia. European Journal of Social Theory, 18(4), 390-412. https://doi.org/10.1177/1368431014568425

Hudders, L., \& Pandelaere, M. (2012). The Silver Lining of Materialism: The Impact of Luxury Consumption on Subjective Well-Being. Journal of Happiness Studies, 13(3), 411-437. https://doi.org/10.1007/s10902011-9271-9

Hunt, J. M., Kernan, J. B., Chatterjee, A., \& Florsheim, R. A. (1990). Locus of Control as a Personality Correlate of Materialism: An Empirical Note. Psychological Reports, 67(3_suppl), 1101-1102. https://doi.org/10.2466/pr0.1990.67.3f.1101

Isaki, C. T., \& Fuller, W. A. (1982). Survey design under the regression superpopulation model. Journal of the American Statistical Association. https://doi.org/10.1080/01621459.1982.10477770

Kózka, A., \& Przybyła-Basista, H. (2016). The relationships between perceived stress and psychological wellbeing among mothers and fathers of children with Down syndrome. The New Educational Review, 44(2), 285-294. https://doi.org/10.15804/tner.2016.44.2.23

Krauss, S., Hamzah, A., \& Idris, F. (2012). Adaptation of a Muslim Religiosity Scale for Use with Four Different Faith Communities in Malaysia. Literature and Arts of the Americas, 49(2), 147-164. Retrieved from http://www.jstor.org/stable/20447486?seq=1\#page_scan_tab_contents

Lefcourt, H. M. (1966). Internal v external control of reinforcement: A review. Psychological Bulletin, 65(4), 214.

Marcuse. (2014). The One-Dimensional Man. Igarss 2014. https://doi.org/10.1007/s13398-014-0173-7.2

Masoom, M. R. (2017). The Control of Externality among the Street Children and Marginalized People of Dhaka City: A Key Indicator to Ensure Sustainable Livelihood. Asian Journal of Humanity, Art and Literature, 4(1), 17-24. Retrieved from http://i-proclaim.my/archive/index.php/ajhal/article/view/297

Masoom, M. R., \& Moniruzzaman Sarker, M. (2017). Rising materialism in the developing economy: Assessing materialistic value orientation in contemporary Bangladesh. Cogent Business \& Management, 4(1). https://doi.org/10.1080/23311975.2017.1345049

Masoom, M. R., \& Sarker, M. M. (2017). The Effect of Materialistic Value-Orientation on Religiosity in Bangladesh: An Empirical Investigation. Religions, 9(1), 6. https://doi.org/10.3390/rel9010006

McCormick, J., Hoekman, K., \& Smith, D. (2000). Religious orientation and locus of control in an Australian Open Enrolment Christian School. In The AARE Annual Conference, The University of New South Wales (p. 11). Sydney. Retrieved from https://www.aare.edu.au/data/publications/2000/mcc00072.pdf

McCullough, M. E., \& Willoughby, B. L. B. (2009). Religion, Self-Regulation, and Self-Control: Associations, Explanations, and Implications. Psychological Bulletin. https://doi.org/10.1037/a0014213

Mirowsky, J., \& Ross, C. E. (2006). Control or Defense? Depression and the Sense of Control over Good and Bad Outcomes. Journal of Health and Social Behavior. https://doi.org/10.2307/2137046

Munir, Z., Muehlstein, O., \& Nauhbar, V. (2015). Bangladesh: The Surging Consumer Market Nobody Saw Coming. Boston, Massachusetts. Retrieved from https://www.scribd.com/document/348288206/BCGBangladesh-Surging-Consumer-Market-Oct-2015-Tcm80-199361

Pargament, K. I. (1997). The psychology of religion and coping: Theory, research, practice.

Rahman, S., \& Marjan, S. M. H. (2014). Fragile Democracy, Indications of Failed State and Lack of Good Governance: Perspective Bangladesh. Journal of Mass Communication \& Journalism, 04(03), 1-7. https://doi.org/10.4172/2165-7912.1000180

Richins, M. L. (1994). Valuing Things: The Public and Private Meanings of Possessions. Journal of Consumer Research, 21(3), 504. https://doi.org/10.1086/209414

Richins, M. L., \& Dawson, S. (1992). A Consumer Values Orientation for Materialism and Its Measurement: Scale Development and Validation. Journal of Consumer Research, 19(3), 303. https://doi.org/10.1086/209304

Rotter, J. B. (1966). Generalized expectancies for internal versus external control of reinforcement. Psychological Monographs: General and Applied, 80(1), 1-28. https://doi.org/10.1037/h0092976

Schreiber, J. B., Stage, F. K., King, J., Nora, A., \& Barlow, E. A. (2006). Reporting structural equation modeling and confirmatory factor analysis results: A review. Journal of Educational Research. https://doi.org/10.3200/JOER.99.6.323-338

Strickland, B. R., \& Shaffer, S. (1971). I-E, I-E, \& F. Journal for the Scientific Study of Religion, 10(4), 366369. https://doi.org/10.2307/1384782

The World Bank. (2016). World Development Indicators. Retrieved from http://databank.worldbank.org/data/reports.aspx ?source=2\&type=metadata\&series=SI.POV.GINI\#adva ncedDownloadOptions 
Zafar, J. (2011). Measuring Religiosity and Workplace Spirituality in Pakistan: A Case Study of Armed Forces and University Teachers. Cross-Cultural https://doi.org/10.3968/j.ccc.1923670020100604.002

Communication,

$6(4)$, 104-111. 